\title{
Reactive Power Management of a Wind Farm to Prevent Voltage Collapse of an Electric Power System
}

\author{
R. M. Monteiro Pereira \\ Instituto Superior Engenharia \\ de Coimbra, Portugal \\ rmfm@isec.pt
}

\author{
C. M. Machado Ferreira \\ Instituto Superior Engenharia de Coimbra \\ and INESC Coimbra, Portugal \\ cmacfer@isec.pt
}

\author{
F. P. Maciel Barbosa \\ INESC TEC and Faculdade Engenharia \\ da Universidade do Porto, Portugal \\ fmb@fe.up.pt
}

\begin{abstract}
Nowadays, the large penetration of wind power generation poses new challenges for dynamic voltage stability analysis of an electric power system. The practical importance of dynamic voltage stability analysis is to help in designing and selecting counter-measures in order to avoid voltage collapse and enhance system stability. The impact of wind integration on reactive reserve requirements is a current area of interest for renewable integration studies and power system operators. In this paper is studied a new wind power plant model with reactive power management. The active power and the frequency management are taken into account too. The developed model can be used to represent, in a simplified way, an entire wind farm in order to simulate the dynamic voltage stability of the system, whatever the technology involved in the wind turbine. The system is completely modelled by a single dynamic converter model with appropriate control loops intended to reproduce the overall response of a wind farm for different grid events, such as faults or voltage and reactive power management at the point of common coupling.
\end{abstract}

Index Terms-Dynamic Voltage Stability, Reactive Power Management, Voltage Collapse, Wind farms.

\section{INTRODUCTION}

The voltage collapse normally involves large disturbances. The most important evidences of voltage collapse are low voltage profiles, heavy reactive power flows in transmission lines, heavily loaded systems and insufficient reactive support [1]. The voltage collapse often require long system restoration, while large groups of customers are left without supply for extended periods of time. Reactive power management and voltage control are playing an increasingly important role as electricity networks experience higher flows and greater variability [2]

With the increased presence of renewable energy sources in the electric power systems during the last years, especially wind energy, many countries have established or are creating a set of specific requirements, grid codes, concerning grid support during steady-state operation and grid faults [3]. The aim of these grid codes is to ensure that the continued expansion of wind power generation does not compromise the power quality, as well as the security and reliability of the electric power network [4]. Consequently, the risk of losing a large portion of wind power generation during fault events decreases and the Transmission System Operators (TSO) can maintain an efficient, reliable and secure system operation even with high wind power penetration levels [5]. During the disturbance period, the wind farms are requested to restore the voltage level back to the nominal value at the connection point, by injecting the required amount of reactive current. The reactive current control of the wind turbines must be used to support the voltage [6].

Currently, there are different models that allow to study the dynamic behaviour of wind farms, such as: wind turbines equipped with a Doubly-Fed Induction Generator (DFIG), wind turbines coupled with an asynchronous generators (with and without pitch control) and variable-speed wind turbines with direct driven synchronous generators.

In this paper is studied a new wind power plant model with active and reactive power management and frequency management. The model was implemented in a test system with a wind farm and conventional generation. The wind farm is represented by a model of the wind turbine equipped with pitch control, coupled with a Fixed Speed Induction Generator (FSIG) [7]. The Automatic Voltage Regulators (AVR), the OvereXcitation Limiter (OXL) of the generating units and the turbine Speed Governors (SG) were modelled. Different load models were used and the Under Load Tap Changer (ULTC) was taken into account too.

Significant disturbances in the test system were modelled, such as: an increase of the wind speed and the tripping of the overhead transmission line were simulated in the studies, using the EUROSTAG software package. Finally, some conclusions that provide a better understanding of how the reactive power management in a wind farm can be used to improve the voltage stability of an electric power system are pointed out.

\section{WIND POWER PLANT MODEL}

The developed model can be used to represent in a simplified way, an entire wind farm for use in system impact studies, whatever the technology involved. In this study the technology involved is a wind turbine equipped with pitch control coupled with a FSIG. The whole system is modelled by a single dynamic converter model with appropriate control loops intended to reproduce the overall response of a wind farm for different grid events, such as short-circuits or voltage and reactive power management at the point of common 
coupling. This model includes wind farms equipped with a power/frequency control for primary reserve participation [8].

\section{A. Active power management}

The active power management of the wind farm is split in three parts.

The first part concerns the calculations of the mechanical power. The performance coefficient $(C p)$ is determined by the aerodynamic law and it is multiplied by the cube of the wind speed. Constant losses and losses proportional to the rotor speed are taken into account.

The second part concerns:

- The calculation of the speed set point according to the active power delivered in the grid. If the active power is above $0.75 \mathrm{pu}$, the speed set point corresponds to the nominal speed. Under $0.75 \mathrm{pu}$, the speed is adapted to extract as maximum power as possible from the wind.

- The mechanical equation calculation to obtain the rotor speed, in function of the active power, the mechanical power and the inertia.

- The active power set point calculation in function of the rotor speed, with limitations on the absolute value of the active power and its variation rate.

- The pitch angle calculation in function of the rotor speed, also with limitations on the absolute value and its variation rate.

Third part concerns the low voltage active current management (LVACM) function. The maximum total current $\left(I_{\max }\right)$ admitted by the model is set to $1.1 \mathrm{pu}$. Equation (1) allows to calculate the total current and at normal operation condition the active current has priority on the reactive current.

$$
I_{t}=\sqrt{I_{p}^{2}+I_{q}^{2}}
$$

where $I t$ is the total current, Ip and $I q$ stand for active and reactive currents respectively.

If the voltage drops, the LVACM function commands the bridge to radically decrease the maximum active current. The goal is to avoid injecting too much active current in a weakened grid because it does not provide the desired active power due to the lowered voltage but, it worsens the stability of the network during the fault and it slows down the voltage recovery after the fault too. When the voltage recovers, the active current increase rate is limited to avoid making the voltage recovery more difficult [8].

Another advantage of this LVACM function is to increase the maximum limit of the reactive current (priority is given to the active current but its maximum limit is decreased, leaving more margin for the reactive power), to inject as much reactive power as possible and support the voltage. Therefore, the maximum accepted reactive current depends on the active injected current.

\section{B. Reactive power management}

The voltage and reactive power management comprise two parts. In the first part the compensated voltage is calculated in order to provide the necessary reactive compensation to meet the requirement at the grid connection point. The difference is made with the compensated voltage set point and enters a proportional and integral regulator with limitations that computes the reactive power set point. Subsequently, the comparison is made with the measured reactive power.

The limitations on the reactive power set point are dependent on the voltage output of the wind turbines. If the voltage is above $0.8 \mathrm{pu}$, it is supposed that the operation is almost at steady-state and the limits applied are those from the capability curve of the wind turbines. Fig. 1 and Fig. 2 show, respectively, the capability curves PQ and VQ used by default in the model.

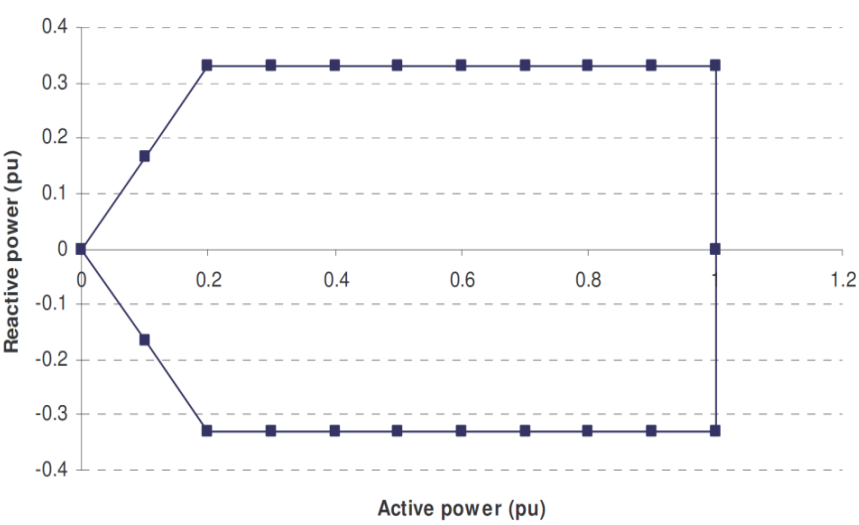

Fig. 1. Capability curve PQ of the wind turbines used by default in the model [8].

In the second part of the reactive power control, the error on reactive power enters another proportional and integral regulation to yield the reactive current. Two limitations are applied. In the first one, monitoring the active current and limit the reactive current, so that the total current does not exceed $1.1 \mathrm{pu}$. The second one is the High Voltage Reactive Current Management that limits the injection of reactive current if the voltage reaches a certain limit.

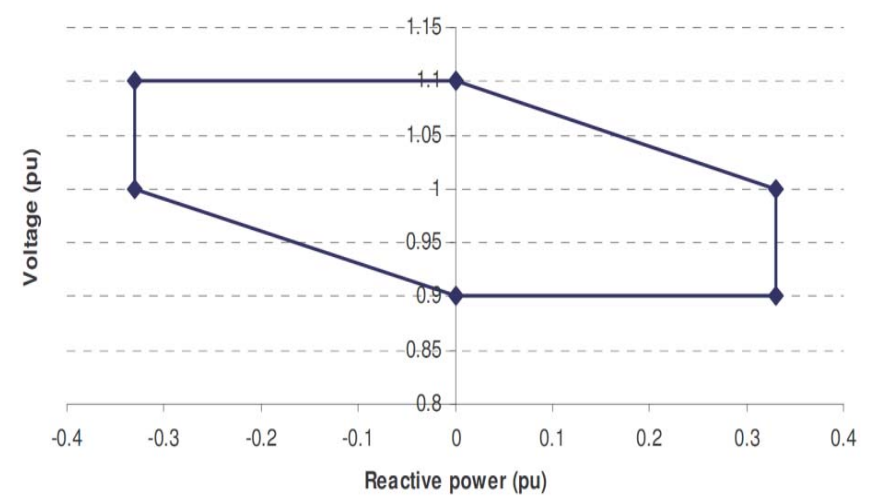

Fig. 2. Capability curve VQ of the wind turbines used by default in the model [8].

\section{Frequency management}

The model of converter used to represent the wind farm requires a few blocks that give the active and reactive current and the frequency. A phase lock loop was then built and implemented in this model to fix the commutation frequency of the converter model [8]. 


\section{APPLICATION EXAMPLE}

In Fig. 3, it is shown the single line diagram of the electric power network that was used in this study. The simulations were carried out considering the network data presented in [9], [10].

Generator G2 is considered as an infinite bus. The AVR and OXL of the generating units and the turbine speed governors were taken into account. The ULTC actions of the power transformer between buses N3 and N4 $(380 / 150 \mathrm{kV})$ are represented considering a time delay and a dead-band. Time delays for ULTC operations were assumed to be $30 \mathrm{~s}$ for the first tap movement and $5 \mathrm{~s}$ for subsequent tap movements.

In this study, the operating point assumed corresponds to a load level of $1600 \mathrm{MW}$ and $850 \mathrm{MVAr}$. In bus N3 it is assumed a load level of $600 \mathrm{MW}$ and 550 MVAr whereas in bus $\mathrm{N} 4$ the active power load is $1000 \mathrm{MW}$ and reactive power load is 300 MVAr. In bus N4 the load was assumed as constant impedance and in bus N3 was assumed as constant power. The wind farm is connected at bus N6 by a three winding transformer $150 / 0.69 / 0.69 \mathrm{kV}$.

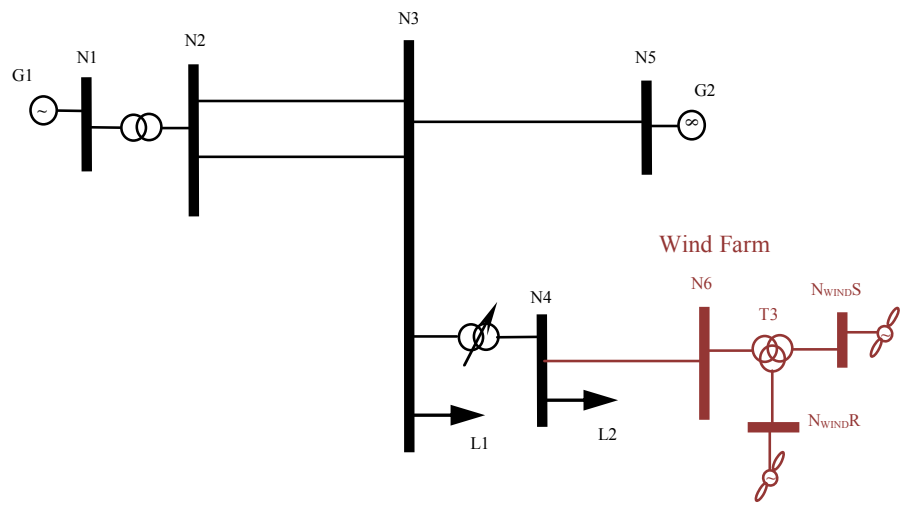

Fig. 3. Single line diagram of the power network.

The wind farm has 80 wind turbines each with 2 MVA and is represented by an aggregated equivalent model. The wind farm was modelled considering that the wind turbines were equipped with pitch control coupled with a FSIG and a shunt capacitor bank with 127 MVAr. In this model the wind speed to obtain a maximal power is $11.5 \mathrm{~m} / \mathrm{s}$.

In this study two scenarios were simulated and analyzed. In the first one (case I) the wind farm was modelled considering that the wind turbines were equipped with pitch control coupled with a FSIG and a shunt capacitor bank, without reactive and active power management and frequency control. In the second situation (case II) the wind farm was modelled considering that the wind turbines were equipped with pitch control coupled with a FSIG and a shunt capacitor bank, with reactive and active power management and frequency control.

In the two cases the following events were simulated:

- an increase of the wind speed from 8.5 to $10.5 \mathrm{~m} / \mathrm{s}$, from $20 \mathrm{~s}$ to $30 \mathrm{~s}$;

- the tripping of the $380 \mathrm{kV}$ overhead transmission line between buses N3 and N5 at $50 \mathrm{~s}$.

\section{RESULTS}

Fig. 4 shows, for case I and case II, the voltage variation in bus N4, the field current of generator G1 and the changes in the transformer taps, corresponding to the power device connected between buses N3 and N4.

In case I, after the occurrence of the tripping of the $380 \mathrm{kV}$ overhead transmission line between buses N3 and N5 at $50 \mathrm{~s}$, the voltage in bus N4 (Fig. 4.a) decreases and, consequently, G1 increase the generation of reactive power. The ULTC changes its position (Fig. 4.c) to increase the voltage in bus N4.This phenomena yields to an additional increase in the generation of the reactive power in G1. The OXL of G1 operates and the field current changes to its maximum value of $3.03 \mathrm{pu}$, at $110 \mathrm{~s}$ (Fig. 4.b). In this case the power network collapses at approximately $240 \mathrm{~s}$.

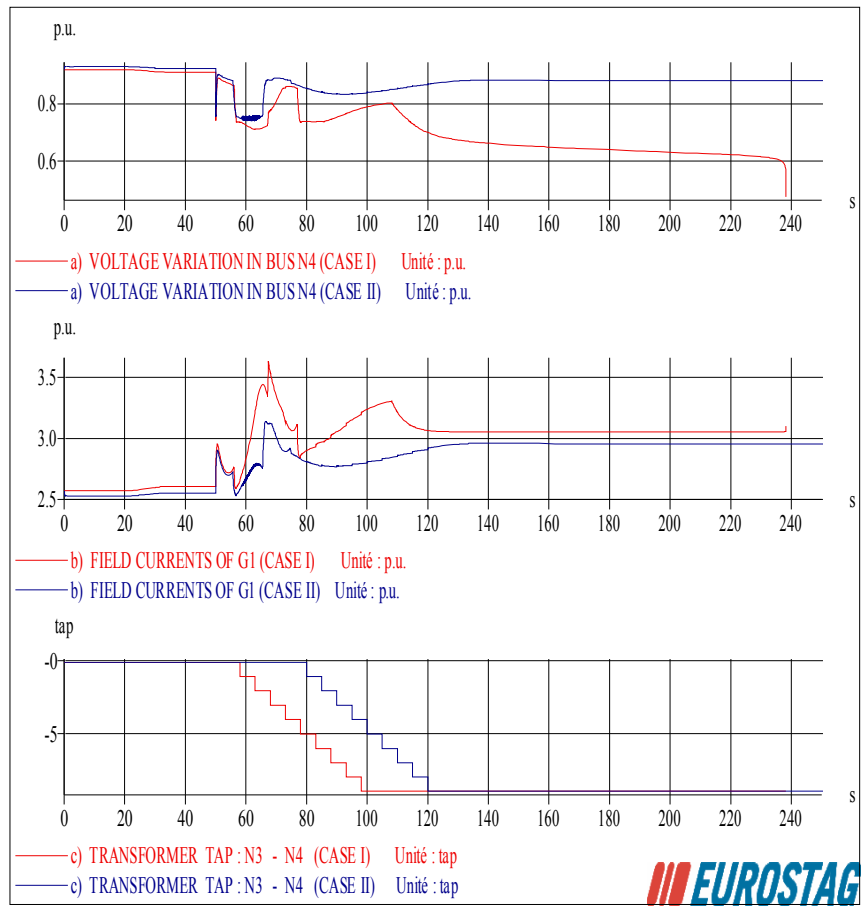

Fig. 4. a) Voltage variation in bus N4, b) Field current of G1, c) ULTC position of transformer between buses N3 and N4.

Fig. 5 presents, for case I and case II, the voltage variation in bus N6, the active power produced by the FSIG, the reactive power consumed by the FSIG and the reactive power injection of the capacitor banks in bus N6.

After the occurrence of the contingency the reactive power injection decreases, due to the voltage dips at bus N6 (Fig. 5.d). The capacitor banks connected in parallel are not effective to prevent the voltage collapse, since the reactive power production diminishes with the terminals voltage decreasing.

The FSIG wind turbine using a squirrel-cage induction generator, usually have the ability to withstand high currents during a voltage dip, due to its high thermal capacity. In this situation, the magnetization must be fast enough in order to prevent the overspeed protection tripping. These machines do not possess the ability to participate in voltage regulation. 
On the contrary, this type of machines consume reactive power (Fig. 5.c), which can lead to a voltage collapse situation as shown in case I.

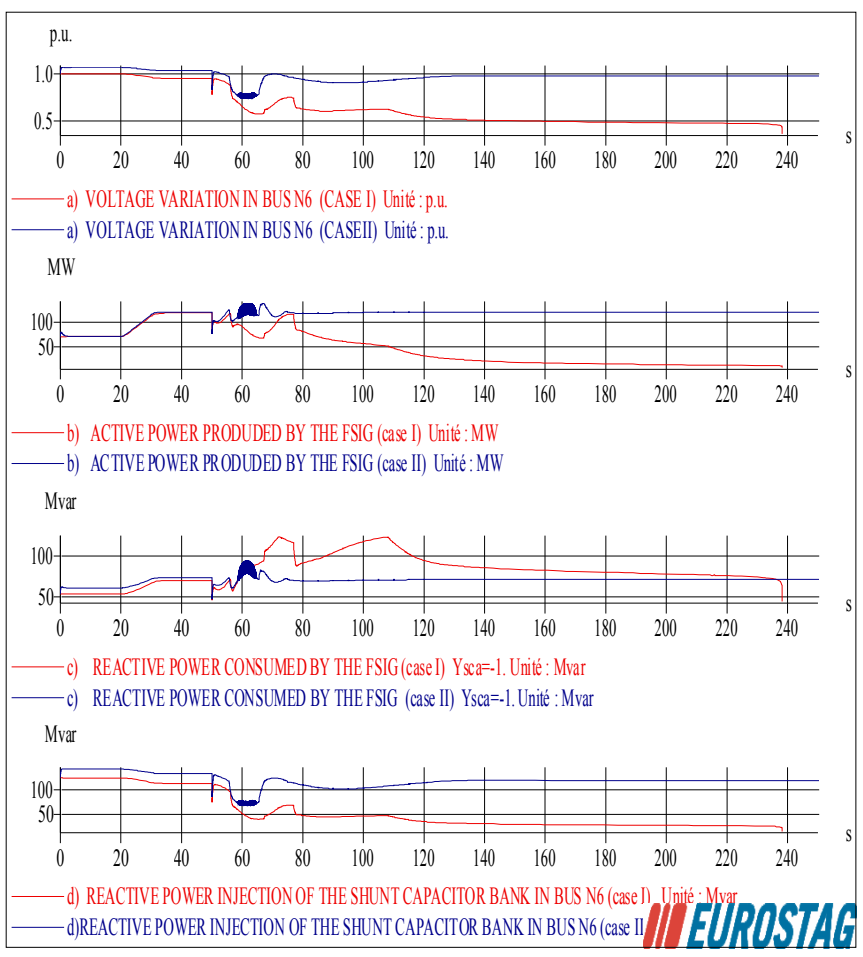

Fig. 5. a) Voltage variation in bus N6, b) Active power produced by the FSIG c) Reactive power consumed by the FSIG, d) Reactive power injection of the shunt capacitor bank in bus N6.

Fig. 6 shows, for case I and case II, the frequency variation at bus N6.

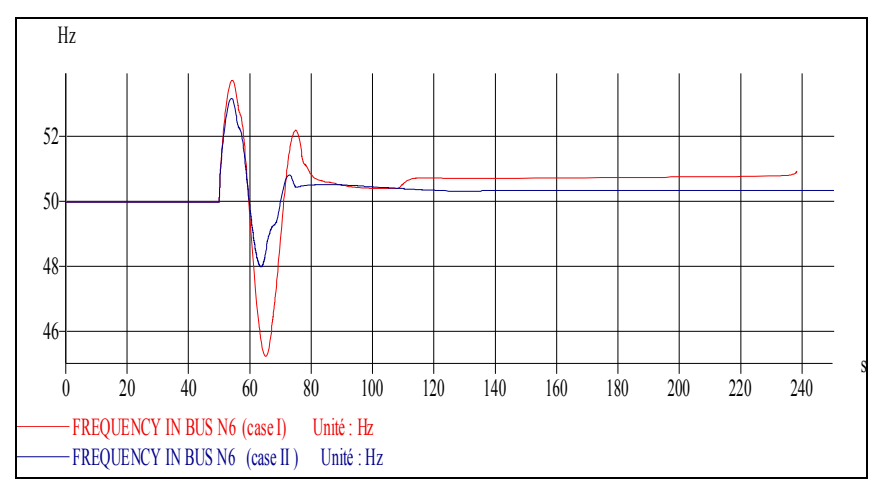

Fig. 6. Frequency at bus N6.

Fig. 7 presents, for case II, the voltage variation, the active power produced by the FSIG, the reactive and the active power management in bus N6.

In case II, using the model with reactive and active power management and frequency control in the wind farm, the bus voltage values are much more stable, the capacitors banks produced more reactive power (Fig. 5.d) when compared with case I. The OXL of G1 do not operates (Fig. 4.b) and consequently avoiding voltage stability problems. In this case de frequency in the bus N6 is more stable when compared with case I (Fig. 6).

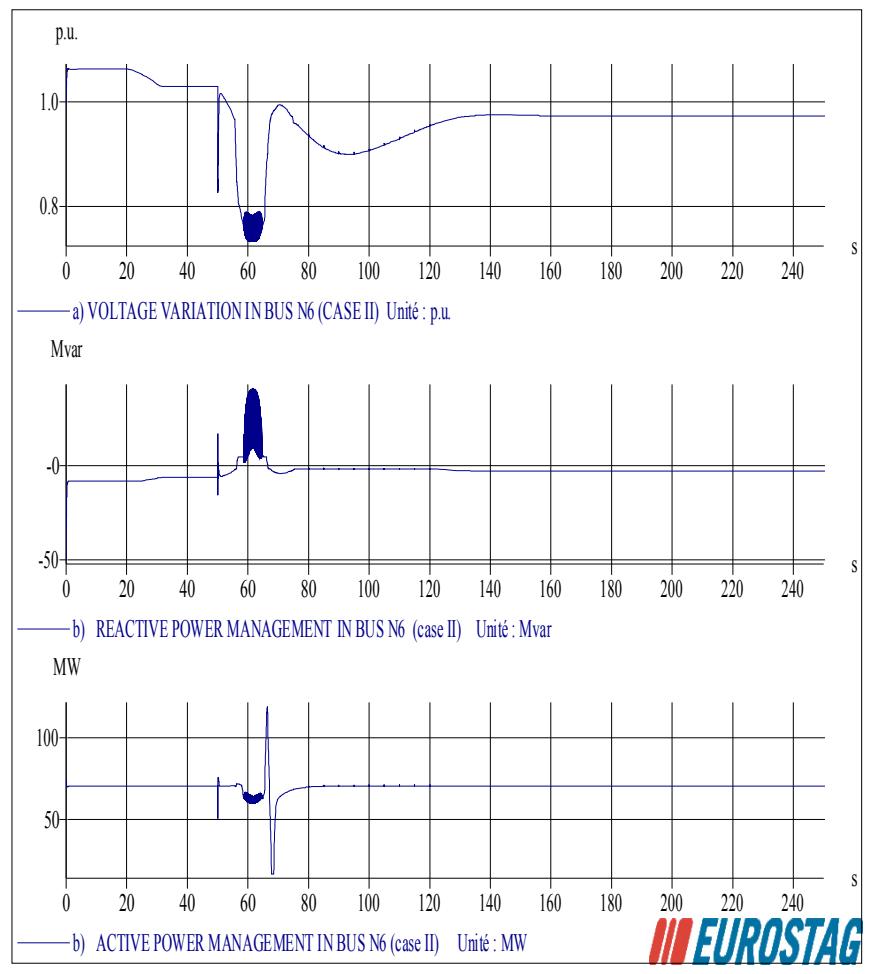

Fig. 7. a) Voltage variation in bus N6, b) Reactive power management in bus N6 c) Active power management in bus N6.

In case II, when the voltage at bus N6 drops below $0.8 \mathrm{pu}$ (Fig.7.a) there are reactive production (Fig.7.b) and during that moment the active power production decreases (Fig.7.c), as it was discussed in section two (Wind Power Plant Model).

\section{CONCLUSION}

This paper presents a study of the reactive power management of a wind farm to prevent voltage collapse of an electric power system. In order to assess the power network voltage stability severe contingencies were simulated.

The wind power plant model with active and reactive power management and frequency management is very useful when used in transient or voltage stability studies during the occurrence of severe disturbances that can originate the collapse of the system. The model has the advantage that can be used in wind farms with generators of different technologies. In the simulation results presented in this study the model was used in a wind farm equipped with FSIG.

This model can be used in wind parks with voltage and frequency control, so that when a disturbance occurs, for example a short-circuit the wind farm is not disconnected from the grid.

The grid codes concerning wind power generation are specific of each country and cover significant technical regulatory issues. The aim of these grid codes is to ensure that the continued expansion of wind power generation does not compromise the power quality, as well as the security and reliability of the electric power network. The sudden disconnection of wind generators, due to a fault may produce an unbalance between the power supply and the power 
demand. Low Voltage Ride Through is one requirements specified by the grid codes, where wind turbines have to stay connected to the network for typical contingencies. The new wind power plant model can be modified in order to comply with requirements of the different grid codes.

\section{REFERENCES}

[1] R. M. Monteiro Pereira, C. M. Machado Ferreira, F. P. Maciel Barbosa "Influence of the Reactive Power Management for Wind Power Plants in the Dynamic Voltage Stability", in Przeglad Elektrotechniczny (Electrical Review), R. 88 NR 1a/2012, pp. 198-201. Available online: http://pe.org.pl/articles/2012/1a/42.pdf.

[2] P. Sharma, D. Thukaram, "Reactive power and voltage control in grid connected wind farms", in Proc. of the 7th IEEE International Conference on Industrial and Information Systems (ICIIS), Indian Institute of Technology Madras, Chennai, India, 6-9 Aug. 2012.

[3] M. Tsili, Ch. Patsiouras, S. Papathanassiou, "Grid code requirements for large wind farms: a review of technical regulations and available wind turbine technologies", in Proc. of the European Wind Energy Conference, EWEC'08, European Wind Energy Association, Brussels, Belgium, Apr. 2008.

[4] Power System Operation Corporation, "Reactive Power Management \& Voltage Control in North Eastern Region", Technical Report, North
Eastern Regional Load Despatch Centre (NERLDC), Shillong, India, Nov. 2012.

[5] P. Panchal, B. Mehta, "Enhancement of Reactive Power Capability of Doubly Fed Induction Generator", International Journal of Electrical Engineering \& Technology (IJEET), Vol. 5, Issue 8, pp. 107-118, Aug. 2014.

[6] Y. Wang, et al., "Fast Coordinated Control of DFIG Wind Turbine Generators for Low and High Voltage Ride Through", Energies, Vol. 7, Issue 7, pp. 4140-4156, Jun. 2014.

[7] R. M. Monteiro Pereira, C. M. Machado Ferreira and F. P. Maciel Barbosa, "DFIG Performance Assessment during Low Voltage Ride through in the Dynamic Voltage Stability of an Electric Power System", 46th International Universities Power Engineering Conference, UPEC2011, South Westphalia University of Applied Sciences, Soest, Germany, 5th-8th September 2011.

[8] Tractebel Energy Engineering and Réseau de Transport d'Electricité (RTE), Eurostag Software user's Manual and Release Notes, Eurostag Package Release 4.5, Jun. 2010.

[9] R. M. Monteiro Pereira, C. M. Machado Ferreira, F. P. Maciel Barbosa, "Comparative study of STATCOM and SVC performance on Dynamic Voltage Collapse of an Electric Power System with Wind Generation", IEEE Latin America Transactions (Revista IEEE América Latina), Vol. 12, Issue: 2, pp. 138-145, Mar. 2014.

[10] Tractebel Energy Engineering and Réseau de Transport d'Electricité (RTE), "Eurostag Tutorial”, Eurostag Package Release 4.5,june 2010. 